\title{
Evaluation of Thermal Comfort Level in Social Interest Housing with Earth Tubes for the Brazilian Bioclimatic Zones 1, 2 and 7
}

\author{
Raquel Ramos Silveira da Mota ${ }^{1}$, Giacomo Orlando Veiga Baptista ${ }^{1}$, Lívia Winkel Fernandes ${ }^{1}$ and Eduardo Grala \\ da Cunha ${ }^{2}$ \\ 1. Post-graduation Program in Architecture and Urbanism, Federal University of Pelotas, Pelotas 96010-020, Brazil \\ 2. Faculty of Architecture and Urbanism, Federal University of Pelotas, Pelotas 96010-020, Brazil
}

\begin{abstract}
The expansion of social housing in Brazil is solving the great demand among low-income populations. However, these projects are not considering climatic factors and thermal comfort strategies. There is a standardization of architectural projects, which leads to the user discomfort. Bioclimatic solutions that improve the thermal performance of buildings should be valued in the projects of buildings. This paper presents a comparative study noticing the thermal comfort provided by a earth tube ventilation system with a natural ventilation system based in the opening of the windows. In this study, three Brazilian bioclimatic zones defined by NBR (Brazilian Standard) 15220 (2005), Zone 1 (Curitiba), 2 (Camaquã) and 7 (Cuiabá), were considered. To make this comparison, computer simulation was used to observe the thermal confort conditions in RTQ-R (Quality Technical Standard for Energy Efficiency Level in Residential Buildings) (2010), with the help of Energy Plus software and Schektch Up with the plug in Open Studio for modeling the residence. After the energy modeling, the results were analyzed with the Analisys Bio software in order to obtain the percentage of hours of comfort for the year $(8,760 \mathrm{~h})$. The conclusion is drawn that the natural ventilation strategy with the opening and closing of the windows is more efficient in Bioclimatic Zone 1. For the Bioclimatic Zone 2, the earth tubes should be used only in the summer and, in Bioclimatic Zone 7, earth tubes are efficient throughout the year because of the high temperatures in the exterior environment.
\end{abstract}

Key words: Social housing, earth tubes, natural ventilation, computer simulation, thermal performance.

\section{Introduction}

The electricity consumption in commercial and residential sectors in Brazil has increased significantly over the last years. Due to economic stability, easier access to credit and the large offer of products, Brazilians began to consume more energy. Considering that the social housing projects are mostly designed with the lower possible cost, without regard to the bioclimatic factors, the thermal comfort level in these houses is very low, leading to higher energy consumption. Low-cost solutions for increasing thermal comfort in SIHs (social interest housing) are

Corresponding author: Raquel Ramos Silveira da Mota, architect, research field: energy efficiency. E-mail: raquelzinhamota@gmail.com. important strategies to improvelife quality of their users.

This paper assesses the level of thermal comfort in a social interesthousing with a natural ventilation system originated from earth tubes, the system being widely discussed because it is a passive method in which there is no spending of energy. It is possible to use a system with forced ventilation, however, once we are dealing with the case of social interest housing, a system with reduced costs will be chosen. This system consists of tubes buried between $0.5 \mathrm{~m}$ and $1.5 \mathrm{~m}$ in depth (with variable diameter and extension) through which the air flows from the outside to the inside of environments through the action of external wind and natural convection. During its course, the air exchanges heat with the soil and enters the environment in milder 
temperatures. Although it is a system already employed in buildings with passive strategies, there are few conclusive studies on its actual effectiveness for Brazilian cities.

The earth tubes have two configurations and can be arranged vertically or horizontally. Fig. 1 shows the example of primary school La Tour de Salvagny, France, where the tubes (made from PVC (polyvinyl chloride) and with 200-mm radius) were arranged horizontally.

Horbach [1] has done studies with the help of computer simulation through the Energy Plus software. These studies acessed the influence of diameter, depth, thickness and length of the earth tubes in the thermal performance of an edification. Next, in Fig. 2, the model is employed by Horbach [1].

Through the analysis of the results, the author concluded that with the decrease of diameter of the tube, the capacity of thermal transference by convection of the said tube has also decreased. As for the length, the authors concluded that the bigger the length, the bigger will be the contact area with the soil,

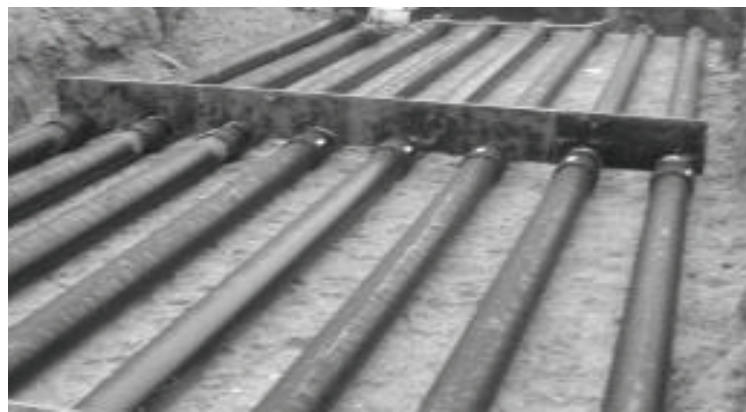

Fig. 1 Earth tubes, La Tour de Salvagny, France [2].

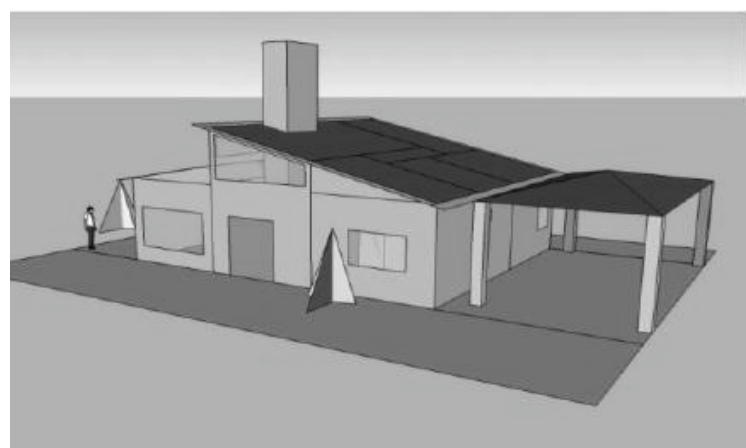

Fig. 2 3D model in Schetch Up.

Source: Horbach [1]. although there is a "saturation point" in wich the variation of temperature inside the tube starts to get smaller. That happens when the temperature of the air becames equal to the temperature on the walls of the tube. The variation in thickness of the tube showed little influence in the air temperature. The differences in the depth of the tubes were almost irrelevant.

Musskopf [3] did a study that consisted of monitoring the Ventura Prototype, in the city of Viamão-RS (Rio Grande do Sul), Brazil, during summer. Concerning air displacement, the study assessed the influence of wind and the difference in temperature on both diameters analysed $(100 \mathrm{~mm}$ and $200 \mathrm{~mm}$ ), both with a $45^{\circ}$ inclination (the upper tubes ascend $2.8 \mathrm{~m}$ in south/south-east direction and the lower ones descend $1.8 \mathrm{~m}$ in north direction), as well as the solar chimney influence. The hygrothermic performance was evaluated comparing the air in the ventilated room with the air in a reference room and with the exterior. Results show that Viamão's soil is effective for the thermal conditioning of the building because it shows a temperature more stable than that of the air in small depths, a temperature close to the annual average air temperature at the location $\left(18^{\circ} \mathrm{C}\right)$. This way, when passing through the tube, the external air gets heated during cold seasons and refrigerated in hot ones, keeping the internal air close to the comfort zone. It was also possible to watch that the main factor responsible for air displacement was external wind, although the differences in temperature between the tube's edges, as well as the difference in temperature between the inside and outside of the building, can not be ignored, for they generate speeds of the same magnitude as the main factor. In the end, the study concludes that the room ventilation has reduced its thermal delay with no harm to its thermal comfort, even showing a reduction in its internal humidity.

\section{Objective}

The paper's main objective is the presentation of a comparative study on the level of thermal comfort 
generated in a social interest habitation with a natural ventilation system built from earth tubes and the level of thermal comfort in an SIH with a natural ventilation system from doors and windows, for Bioclimatic Zones 1, 2 and 7. Fig. 3 characterizes brazilian bioclimatic zoning according to the NBR 15220, Part 3 [4].

\section{Methodology}

The study was developed in 10 stages, as seen hereinafter:

(1) bibliographic review;

(2) social interest housing modelling on schetchupsoftware with the Open Studio plug-in;

(3) configuration of the use and occupancy parameters according to the RTQ-R [5];

(4) configuration of housing envelope;

(5) configuration of natural ventilation and artificial air conditioningparameters;

(6) preliminary sizing of earthtubes;

(7) soil temperature calculation;

(8) earth tubes configuration;

(9) running the energy modeling for Bioclimatic Zones 1, 2 and 7;

(10) analysis of the results with the help of Analysis Bio software.

\section{Results Analysis}

\subsection{Bibliographic Review}

In the bibliographical research, several literatures regarding modeling and performanceof buildings with earth tubes were used. The bibliographic review was based mainly on the works of Horbach [1] and Musskopf [3].

\subsection{Modeling of Social Interest Housing in the Schetch Up Software with the Open Studio Plug-In}

The housing was modeled according to Oliveira's [6] study, presenting a combined living room/kitchen, two bedrooms and a bathroom. With a full area of $46.8 \mathrm{~m}^{2}$, the computational model can be seen in Fig. 4 .

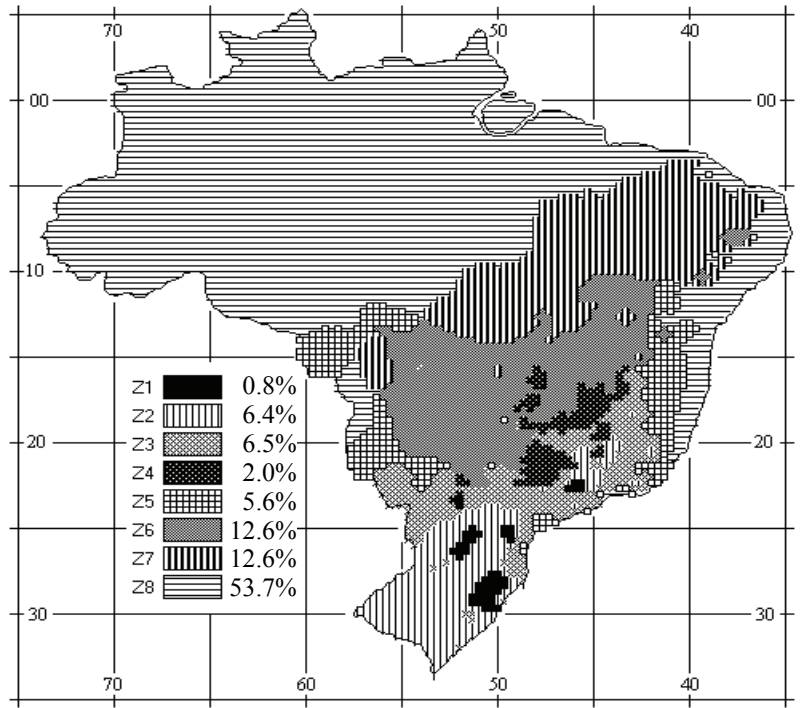

Fig. 3 Brazilian bioclimatic zoning.

Source: NBR 15220 [4].

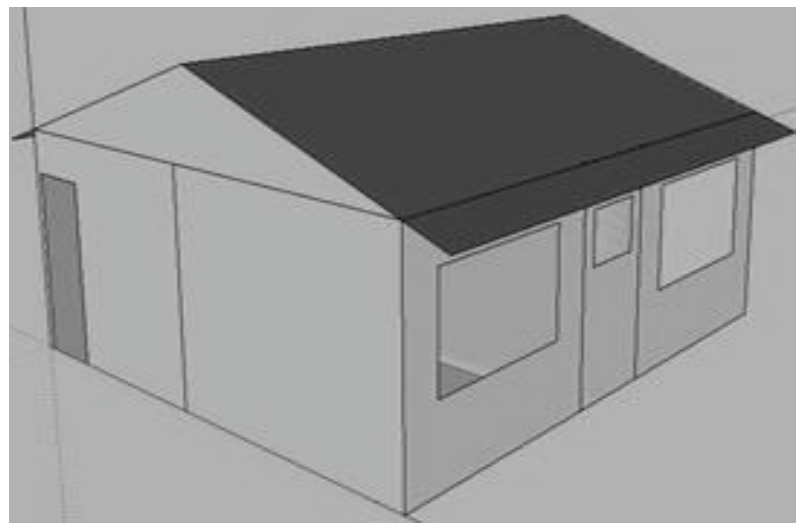

(a)

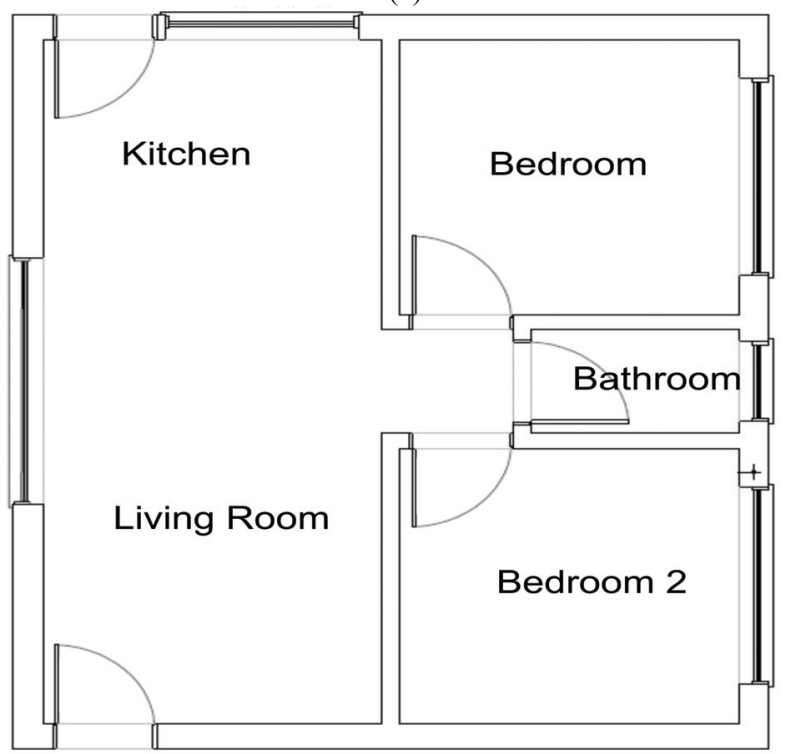

(b)

Fig. 4 Housing project: (a) 3D model (in Schetch Up); (b) ground plan. 
4.3 Configuration of the Use and Occupancy Parameters According to the RTQ-R

The parameters for energy modeling of use and occupation used are the ones in the RTQ-R (Quality Technical Standard for the Energy Efficiency of Residential Buildings) [5].

Each environment has been modeled as a thermal area, including the attic, as per the standard [5]. The roof overhang was modeled with the shading group option. The pattern of occupancy is two persons per bedroom and the total number of residents in the living room, therefore, two people in each bedroom and four in the living room/kitchen.

The installed lighting power density recommended is $6 \mathrm{~W} / \mathrm{m}^{2}$ for the living room and $5 \mathrm{~W} / \mathrm{m}^{2}$ for the dormrooms. Regarding electrical appliances, $1.5 \mathrm{~W} / \mathrm{m}^{2}$ in a 24-h period was used, only in the living room.

Regulation indicates as metabolic rate $108 \mathrm{~W}$ for the living room and $81 \mathrm{~W}$ for the dormrooms, both for a $1.80-\mathrm{m}^{2}$ skin area. An Energy Plus preprocessor (slab) was used for soil temperature calculation.

\subsection{Configuration of Materials Used in Housing}

The materials employed in the modeled housing are specified in Table 1.

\subsection{Configuration of Natural Ventilation and Artificial Air Conditioning Parameters}

Regarding natural ventilation, the surrounding roughness coefficient $(\alpha)$ used was 0.33 , which represents an urban center lot in wich at least $50 \%$ of the buildings are higher than $21 \mathrm{~m}$. The $D C$ (discharge coefficient) for rectangular windows and doors was 0.60 , the CQ (gap air flow coefficient) was 0.001 $\mathrm{kg} / \mathrm{s} \cdot \mathrm{m}$ and the air flow exponent $(n)$ was 0.65 .

\subsection{Preliminary Sizing of Earth Tubes}

For the preliminary sizing of earth tubes surface, considering a stationary heat exchange system, taking into account the summer situation (cooling), a simplified equation was employed (Eq. (1)). A thermal cooling load was defined and, considering soil, ambience and external temperatures, as well as the convective coefficient, the necessary tube area was set:

$$
Q_{c}=h_{c} \times \Delta t \times A
$$

where:

$Q_{c}=$ heat flow through convection (W);

$h_{c}=$ convective coefficient-variating from $2 \mathrm{~W} /\left(\mathrm{m}^{2} \cdot{ }^{\circ} \mathrm{C}\right)$ to $30 \mathrm{~W} /\left(\mathrm{m}^{2} \cdot{ }^{\circ} \mathrm{C}\right)\left(8 \mathrm{~W} /\left(\mathrm{m}^{2} \cdot{ }^{\circ} \mathrm{C}\right)\right.$ - for low air speed) (Table 2);

$A=$ earth tube contact area $\left(\mathrm{m}^{2}\right)$;

$\Delta t=$ temperature difference (Givoni's comfort zone limit, $29^{\circ} \mathrm{C}$ ).

The thermal load used in the $Q_{c}$ for the living room/kitchen and the bedrooms was obtained in the Energy Plus software with a simulation of a typical summer day. For the convective coefficient, $0.5 \mathrm{~m} / \mathrm{s}$ was the chosen value for air speed through the tubes, resulting, therefore, in $h_{c}=10 \mathrm{~W} /\left(\mathrm{m}^{2} \cdot{ }^{\circ} \mathrm{C}\right)$.

Temperatures of $\Delta t$ correspond to internal environments temperature obtained in the typical day (January 10) through simulation and the external temperature in the typical day obtained from the weather file. The result of Eq. (1) is presented:

$$
\begin{gathered}
6,776.08=10 \times(25-20.3) \times A \\
A=144.71 \mathrm{~m}^{2}
\end{gathered}
$$

The sizing for three tubes with a $0.2-\mathrm{m}$ diameter

Table 1 Table with materials employed in housing.

\begin{tabular}{llcc}
\hline Material & $\begin{array}{l}\text { Conductivity } \\
(\mathrm{W} / \mathrm{m} \cdot \mathrm{K})\end{array}$ & $\begin{array}{l}\text { Density } \\
\left(\mathrm{kg} / \mathrm{m}^{3}\right)\end{array}$ & $\begin{array}{c}\text { Specific heat } \\
(\mathrm{J} / \mathrm{kg} \cdot \mathrm{K})\end{array}$ \\
\hline Solid brick (11-cm) & 1.05 & 2,000 & 920 \\
Mortar & 1.15 & 1,800 & 1,000 \\
Tile/ceramic floors & 1.05 & 2,000 & 920 \\
Slab (12-cm) & 1.75 & 2,300 & 1,000 \\
Wood & 0.15 & 608 & 1,630 \\
\hline
\end{tabular}

Table 2 External surface thermal conductance variation $\left(h_{e}\right)$ [7].

\begin{tabular}{lll}
\hline Wind type & Speed $(\mathrm{m} / \mathrm{s})$ & $h_{e}\left(\mathrm{~W} / \mathrm{m}^{2} \cdot{ }^{\circ} \mathrm{C}\right)$ \\
\hline Calm air & 0.1 & 8 \\
Very week & 0.5 & 10 \\
Week & 1 & 13 \\
Medium & 3 & 21 \\
Strong & 9 & 35 \\
Very strong & 18 & 50 \\
\hline
\end{tabular}


results in $48.057 \mathrm{~m}^{2}$ area and $76.5 \mathrm{~m}$ in length.

\subsection{Soil Temperature Calculation}

The types of soil chosen for the simulation were the heavy and moist soil and the covert and moist soil, because those portrait the most real situation and are favorable to the installation of earth tubes. In Table 3, it is possible to identify the conductivity of the four soil types available as options in the Energy Plus software.

\subsection{Earth Tubes Configuration}

The basic equation used by Energy Plus to calculate

Table 3 Thermal conductivity for different types of soil [8].

\begin{tabular}{lll}
\hline Soil & $\begin{array}{l}\text { Conductivity } \\
\left(\mathrm{W} / \mathrm{m}^{\circ} \mathrm{C}\right)\end{array}$ & Diffusivity $\left(\mathrm{m}^{2} / \mathrm{s}\right)$ \\
\hline Heavy soil (saturated) & 2.42 & 9.04 \\
Heavy soil (moist) & 1.30 & 6.45 \\
Heavy soil (dry) & 0.865 & 5.16 \\
Light soil (dry) & 0.346 & 2.80 \\
\hline
\end{tabular}

Table 4 Tubes configuration.

\begin{tabular}{ll}
\hline Field & Object \\
\hline Zone name & Sala \\
Schedule name & Tubos \\
enterrados \\
Design flow rate $\left(\mathrm{m}^{3} / \mathrm{s}\right)$ & 0.0157 \\
Minimum zone temperature when cooling $\left({ }^{\circ} \mathrm{C}\right)$ & 20 \\
Maximum zone temperature when heating $\left({ }^{\circ} \mathrm{C}\right)$ & 25 \\
Delata temperature $\left({ }^{\circ} \mathrm{C}\right)$ & 11.1 \\
Earth tube type & Natural \\
Fan pressure rise $($ Pa) & 0 \\
Fan total efficiency & 1 \\
Pipe radius $(\mathrm{m})$ & 0.1 \\
Pipe thickness $(\mathrm{m})$ & 0.01 \\
Pipe length $(\mathrm{m})$ & 76.5 \\
Pipe thermal conductivity $(\mathrm{W} / \mathrm{m} \cdot \mathrm{K})$ & 0.19 \\
Pipe depth under ground surface $(\mathrm{m})$ & 4 \\
Soil condition & Heavy and \\
Average soil surface temperature $\left({ }^{\circ} \mathrm{C}\right)$ & damp \\
Amplitude of soil surface temperature $\left({ }^{\circ} \mathrm{C}\right)$ & 20.66 \\
Phase constant of soil surface temperature & 5.73 \\
$($ days $)$ & 118 \\
Constant term flow coefficiency & 1 \\
Temperature term flow coefficiency & 0 \\
Velocity term flow coefficiency & 0 \\
Velocity squared term flow coefficiency & 0 \\
\hline Source: Energy & \\
\hline
\end{tabular}

Source: Energy Plus software screen. the air flow rate of an earth tube is:

$$
\begin{gathered}
\text { Earth tube flow rate }= \\
E_{\text {design }} \times F_{\text {schedule }}\left[\mathrm{A}+B\left(T_{\text {zone }}-T_{\text {odb }}\right)+\right. \\
\left.C_{\text {wind speed }}+D_{\text {wind speed }}\right]^{2}
\end{gathered}
$$

where:

$$
\begin{aligned}
& E_{\text {design }}=\text { tube's air outflow in } \mathrm{m}^{3} / \mathrm{s} ; \\
& F_{\text {schedule }}=\text { tasks schedule that modifies the tube's }
\end{aligned}
$$
outflow;

A = soil thermal constant, dimensionless;

$B=$ the difference between the dry bulb air internal and external temperatures, given in ${ }^{\circ} \mathrm{C}$;

$\left(T_{\text {zone }}-T_{\text {odb }}\right)$ : It is the difference of dry bulb air temperature $\left({ }^{\circ} \mathrm{C}\right)$ between the interior and exterior, under which the earth tube is turned off;

$C_{\text {wind speed }}$ is the wind speed that is active outside the building, given in $\mathrm{m} / \mathrm{s}$;

$D_{\text {wind speed }}$ is the internal tube air speed in $\mathrm{m} / \mathrm{s}$.

To get to the outflow value, we have used the following equation:

$$
\begin{gathered}
A=\pi \times r^{2} \\
A=3.14 \times 0.10^{2}=0.0314 \mathrm{~m}^{2} \\
V=0.0314 \times 0.5=0.0157 \mathrm{~m}^{3} / \mathrm{s}
\end{gathered}
$$

where, $V$ is the outflow value.

The tubes were buried $4 \mathrm{~m}$ deep. The material is PVC and we chose not to use the help of ventilators, taking into account the low cost of the social interest housing buildings. Table 4 shows the tubes configuration.

\subsection{Running the Model Simulation for Bioclimatic Zones 1, 2 and 7}

The simulations were run regarding the reccomended configurations from RTQ-R for natural ventilation during the day and artificial climate control for the night. Regarding natural ventilation, two situations for each bioclimatic zone were analysed:

(1) day natural ventilation (windows and doors)/air conditioning at night;

(2) day natural ventilation (earth tubes)/air conditioning at night.

Having the day's time frame as 9:00 a.m. to 9:00 p.m. and the night as 9:00 p.m. to 9:00 a.m., 
these configurations were simulated for Bioclimatic Zone 1, consisting of the city of Curitiba (latitude: $-49.2733^{\circ}$; longitude: $-25.4284^{\circ}$; 3-h time difference; 925-m high), for Bioclimatic Zone 2, using the city of Camaquã (latitude: $-30.85^{\circ}$; longitude: $-51.8^{\circ} ;-3-\mathrm{h}$ time difference; 108-m high) and for Bioclimatic Zone 7, using the city of Cuiabá (latitude: -56.094894 ; longitude: $-15.5989173^{\circ}$; $-4-\mathrm{h}$ time difference; $176-\mathrm{m}$ high).

\subsection{Analysis of the Thermal Comfort Level with Help from Analysis Bio Software}

Through the Analysis Bio software, we have obtained the annual thermal comfort hours $(8,760 \mathrm{~h})$, inserting into the program data regarding operational air temperature and relative air humidity. So, the software can generate a TRY file and later analyze the Givoni's bioclimatic chart.

Using the Analysis Bio software, we reached the result for Bioclimatic Zone 1, with earth tubes during the day and air conditioning by night (Fig. 5) equal to $55.1 \%$ comfort, the discomfort being aproximately $1 \%$ for cold and $43.9 \%$ for heat.

The model with natural ventilation during the day and air conditioning at night (Fig. 6) presented 45.9\% comfort hours, the discomfort being $39.5 \%$ due to cold and $14.5 \%$ to heat.

At Bioclimatic Zone 2 (Fig. 7), the results for earth tubes during the day and air conditioning by night are $97.4 \%$ comfort hours, the discomfort being $0.01 \%$ due to cold and $2.58 \%$ to heat.

The results for Bioclimatic Zone 2 (Fig. 8), with natural ventilation during the day and air conditioning at night, were $63.4 \%$ comfort, the discomfort beeing $36.1 \%$ due to cold and $0.51 \%$ to heat. The results with the earth tube model are more favorable.

In Bioclimatic Zone 7 (Fig. 9), the result for the model with earth tubes during the day and air conditioning at night was $97.8 \%$ comfort hours, the discomfort being $0.01 \%$ due to cold and $1.3 \%$ to heat.
As for the model with natural ventilation during the day and air conditioning at night (Fig. 10), the result was $98.9 \%$ comfort hours, the discomfort beeing $0.01 \%$ due to cold and $1.04 \%$ to heat. Results for Bioclimatic Zone 7 showed little difference between the simulated models.

Next, in Table 5, a compilation of thermal comfort indexes for the three bioclimatic zones is studied, obtained using the Analys Bio software.

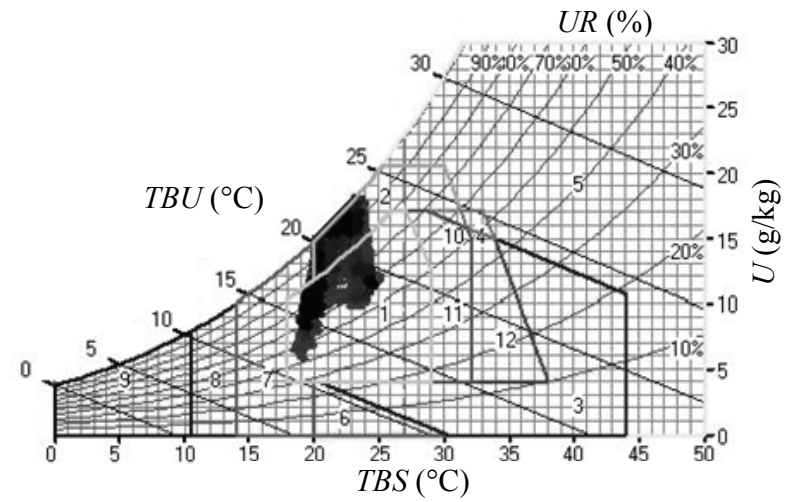

Fig. 5 Zone 1: earth tubes during the day and air conditioning at night (one year, 8,760 h plotted in the Givoni bioclimatic chart).

$T B U$-wet-bulb temperatur $\left({ }^{\circ} \mathrm{C}\right) ; U$-absolute humidity (water vapor $(\mathrm{g}) /$ dry air $(\mathrm{kg})) ; \quad U R$-relative humidity (\%); $T B S$ - dry-bulb temperatur $\left({ }^{\circ} \mathrm{C}\right)$;

Zone 1-thermal comfort; Zone 2-natural ventilation; Zone 3-evaporative cooling; Zone 4-thermal mass; Zone 5-air conditionning system; Zone 6-damping; Zone 7-thermal mass; Zone 8-passive solar heating; Zone 9-heating; Zone 10-natural ventilation and thermal mass; Zone 11-natural ventilation, thermal mass and evaporative cooling; Zone 12-thermal mass and evaporative cooling.

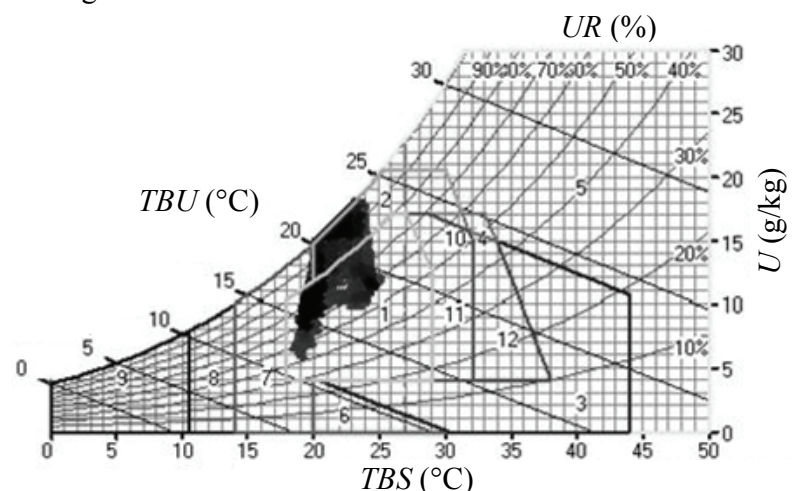

Fig. 6 Zone 1: natural ventilation during the day and air conditioning at night. 


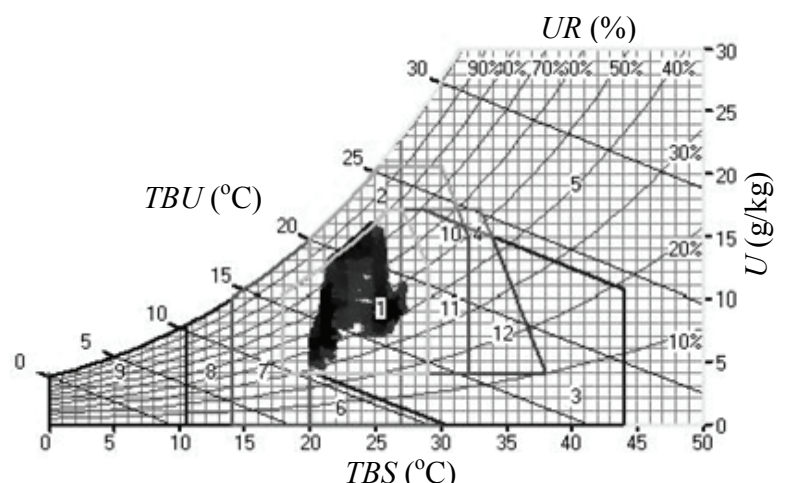

Fig. 7 Zone 2: earth tubes during the day and air conditioning at night.

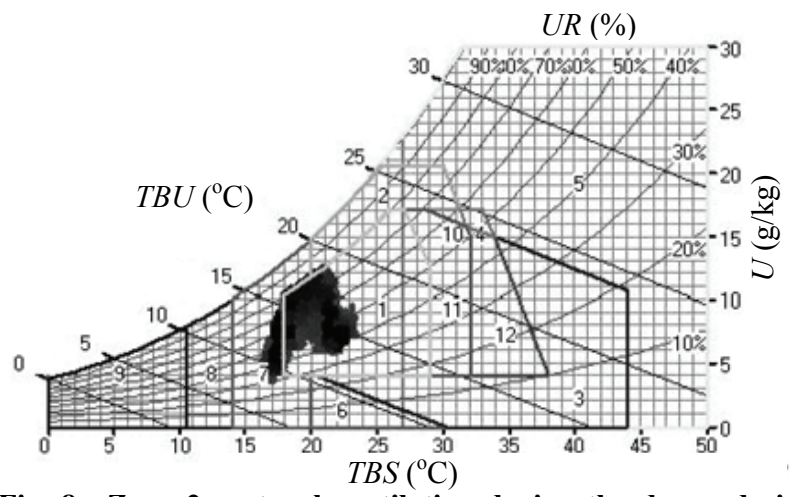

Fig. 8 Zone 2: natural ventilation during the day and air conditioning at night.

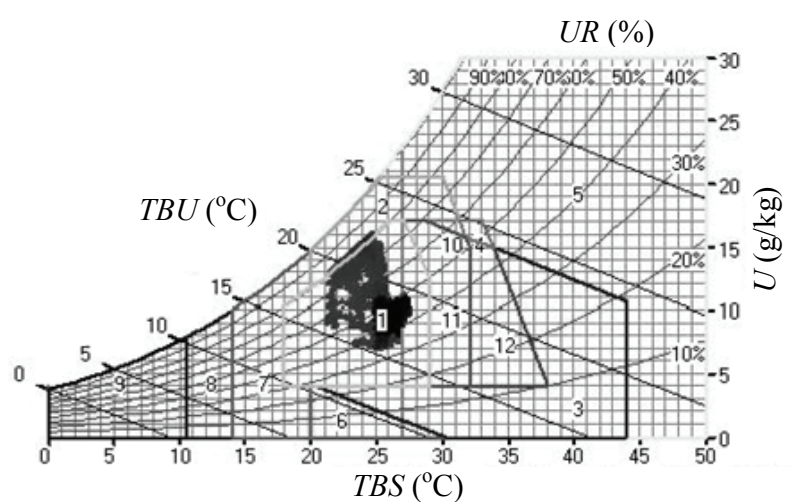

Fig. 9 Zona 7: earth tubes during the day and air conditioning at night.

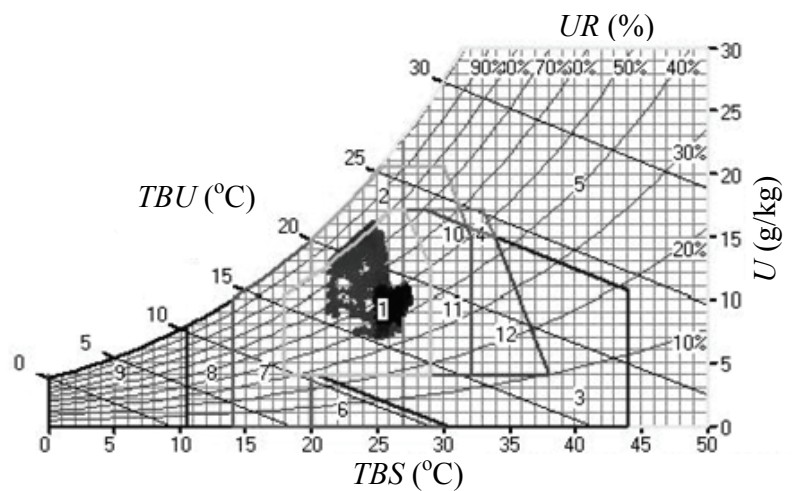

Fig. 10 Zone 7: natural ventilation during the day and air conditioning at night.

Table 5 Compilation of thermal comfort indexes.

\begin{tabular}{|c|c|c|c|c|c|c|}
\hline \multirow{3}{*}{$\begin{array}{l}\text { Thermal comfort } \\
\text { indexes }\end{array}$} & \multicolumn{3}{|c|}{$\begin{array}{l}\text { Natural ventilation (windows) day and } \\
\text { AC (air conditioning) night (\%) }\end{array}$} & \multicolumn{3}{|c|}{$\begin{array}{c}\text { Natural ventilation (earth tubes) day } \\
\text { and AC night (\%) }\end{array}$} \\
\hline & \multirow{2}{*}{ Comfort } & \multicolumn{2}{|c|}{ Discomfort } & \multirow{2}{*}{ Comfort } & \multicolumn{2}{|c|}{$\begin{array}{r}\text { Discomfort } \\
\end{array}$} \\
\hline & & Cold & Heat & & Cold & Heat \\
\hline ZB1 & 45.9 & 39.5 & 14.6 & 55.1 & 1 & 43.9 \\
\hline ZB2 & 63.4 & 36.1 & 0.5 & 97.4 & 0.01 & 2.6 \\
\hline ZB7 & 98.9 & 0.01 & 1.09 & 97.8 & 0.01 & 1.19 \\
\hline
\end{tabular}

\section{Conclusions}

The conclusions first address the suitability of passive thermal conditioning strategies to the NBR 15220, Brazilian standard for thermal performance in social interest housing. Secondly, we feature the performance of earth tubes as natural ventilation strategy for three Brazilian bioclimatic zones, covering cold and hot, dry and moist weather. The NBR 15220 proposes constructive guidelines for each Brazilian bioclimatic zone, which can be related to the results obtained. The standard suggests that for Bioclimatic Zone 1, the coldest of Brazil, we should use passive solar heating only for the winter and heavy internal walls (thermal inertia), noting that the passive conditioning is insufficient for the coldest period of the year. The results both, with earth tubes and the natural ventilation through open windows in winter, indicated that natural ventilation is sufficient for much of the period. For this area, in summer, the use of passive thermal conditioning is not enough.

In Bioclimatic Zone 2, the standard recommends the use of crossed ventilation in summer and solar heating and heavy internal walls for the winter, noting that the passive conditioning will be insufficient during the coldest period of the year.The presented 
Tubes for the Brazilian Bioclimatic Zones 1, 2 and 7

result shows that the hours of discomfort are mainly in winter. The earth tubes strategy proved effective drastically reducing the level of discomfort in winter. The chart also indicates that when using crossed ventilation during the day and air conditioning at night, we should also employ high thermal inertia and solar heating.

The passive thermal conditioning strategies for Bioclimatic Zone 7, according to NBR 15220, are recommended only for summer, being evaporative cooling and selective ventilation (in hot periods, when the internal temperature is higher than the external one). The results for the area were very satisfactory, showing comfort most of the time. The earth tube strategy proved itself effective all year around in this zone.

In Bioclimatic Zone 1, the earth tubes have obtained a better result than the natural ventilation by opening windows, emphasizing that this is an area with low temperatures in winter, with great discomfort by cold in this situation. In Bioclimatic Zone 2, there is large thermal amplitude and high humidity, with discomfort mostly due to cold during the winter. The earth tubes have contributed to the increased level of thermal comfort. In Bioclimatic Zone 7, the tubes behave well throughout the year due to low thermal amplitude, high temperature and low humidity, as well as a result of the soil temperature being predominantly lower than that of the air.

\section{References}

[1] Horbach, C. S. 2010. "Studies in Ventilation Systems with Earth Tubes." Monograph, Department of Mechanical Engineering, Federal University of Rio Grande do Sul. (in Portuguese)

[2] European Commission. 2014. Primary School in La Tour de Salvagny. European Commission. Accessed October 2, 2014. http://www.sara-project.net/article.php3?id_article $=13$.

[3] Musskopf, D. B. 2006. "Exploratory Study on Natural Ventilation with Earh Tubes." M.Sc. dissertation, Federal University of Rio Grande do Sul, Brazil. (in Portuguese)

[4] Brazilian Association of Technical Standards. 2005. NBR 15220-3-Thermal Performance of Buildings. Part 3: Brazilian Bioclimatic Zoning and Constructive Guidelines for Single-Family Social Housing. Rio de Janeiro: Brazilian Association of Technical Standards. (in Portuguese)

[5] INMETRO (National Institut of Metrology). 2010. Quality Technical Standard for Energy Efficiency Level in Residential Buildings, RTQ-R. Rio de Janeiro: Eletrobras. (in Portuguese)

[6] Oliveira, L. S. 2012. "Assessing the Limits of Thermal Properties of Opaque Closures from NBR 15220-3 for Social Housing, Bioclimatic Zone 2.” M.Sc. dissertation, UFPEL (Federal University of Pelotas). (in Portuguese)

[7] Frota, A. B., and Schiffer, S. R. 1987. Thermal Confort Manual. 2nd ed. San Paulo: Studio Nobel. (in Portuguese)

[8] França, S. R. P. 2011. "Simulation Aiming at Residential Ventilation through Earth Tubes." Monograph, Department of Mechanical Engineering, Federal University of Rio Grande do Sul. (in Portuguese). 